\title{
Method for measuring rice grain internal damage degree undergoing threshing force
}

\author{
Hui Ren, Zhong Tang*, Xiyao Li, Yu Li, Xin Liu, Biao Zhang, Yaoming Li \\ (Key Laboratory of Modern Agricultural Equipment and Technology, Ministry of Education, Jiangsu University, \\ Zhenjiang 212013, Jiangsu, China)
}

\begin{abstract}
During the threshing process of rice, the grains fall off the head of the rice ear due to the impact of the threshing bar. At the same time, the impact force of the threshing element causes a certain degree of damage to the grain. However, there are relatively few methods to analyze the internal damage of rice grains during the threshing process. In this study, the connection force between rice grains and stalks and the compressive bearing capacity of the grains were tested on a push-pull test machine, and then the critical impact force and velocity of rice grains during plastic deformation and brittle fracture were obtained by Hertz theory. On this basis, the quantitative evaluation model of grain internal damage was established through the extraction and calculation of the damaged area inside the grain, and the damage degrees inside the grain under different loading times and loading forces were analyzed. The results showed that the average threshing force required for rice grains is $1.57 \mathrm{~N}$ (variance is 0.0529 ), and the critical impact forces for plastic deformation and brittle fracture of the grains during threshing are $138.79 \mathrm{~N}$ and $145.77 \mathrm{~N}$. Since the threshing force during the threshing process was 43.9-71.9 N, it could be known from the internal damage model that the grain is in the safe loading area. Under the same load, the vertical pressure causes the most damage, the lateral pressure takes second place, and the positive pressure was the least. The results of this study can provide a basis for the development of combine harvester and rice grains damage evaluation.
\end{abstract}

Keywords: threshing process, internal damage of grain, threshing force of roller, plastic deformation, critical impact force DOI: $10.25165 /$ j.ijabe.20211401.5750

Citation: Ren H, Tang Z, Li X Y, Li Y, Liu X, Zhang B, Li Y M. Method for measuring rice grain internal damage degree undergoing threshing force. Int J Agric \& Biol Eng, 2021; 14(1): 63-73.

\section{Introduction}

Rice is the staple food of more than 3 billion people in the world, and the world produces about 450 million $t$ of rice every year ${ }^{[1,2]}$. At present, the harvesting of rice mainly depends on mechanization, but mechanical threshing causes some damage to rice grains. Under the influence of mechanical threshing structure, there are some phenomena such as crushing and stress crack. Damage to grains after harvest will seriously affect the quality and economic value of grains ${ }^{[3]}$. Therefore, proposing a model and method to evaluate the degree of damage inside rice grains by studying the causes of damage during rice grain threshing is of great significance for improving the structure and parameters of the rice threshing device. Threshing is an important part of the mechanical rice harvest. If the threshing force of the threshing bar is too small, there will be the phenomenon of incomplete threshing which causes the loss of grain. However, the excessive force of the threshing bar will cause internal damage to the grains. The

Received date: $2020-2-21 \quad$ Accepted date: 2020-11-02

Biographies: Hui Ren, Undergraduate, research interest: intelligent harvesting machinery, Email: 794652594@qq.com; Xiyao Li, Undergraduate, research interest: intelligent harvesting machinery, Email: 2037163011@qq.com; Yu Li, Master candidate, research interest: intelligent harvesting machinery, Email: 169909413@qq.com; Xin Liu, Undergraduate, research interest: intelligent harvesting machinery, Email: 1125378369@qq.com; Biao Zhang, Undergraduate, research interest: intelligent harvesting machinery, Email: 1027540269@qq.com; Yaoming Li, PhD, Professor, research interest: intelligent harvesting machinery, Email: ymli@ujs.edu.cn.

*Corresponding author: Zhong Tang, PhD, Associate Researcher, research interest: intelligent harvesting machinery. School of Agricultural Equipment Engineering, Jiangsu University, Zhenjiang 212013, Jiangsu, China. Tel: +86511-88797338, Email: tangzhong2012@126.com. damage of rice grains during the threshing process is not only related to the structure and motion parameters of the threshing device, but also the compressive bearing capacity of the grains ${ }^{[4]}$. Because the threshing process is very complicated, the interaction between the threshing bar and rice during the threshing process is difficult to describe quantitatively. At present, it is difficult to study the effect of rice threshing on grain damage.

The mechanical properties of rice grains are the mechanical characteristics of rice grains under different external loads, including the destructive force, Poisson's ratio, elastic modulus and other mechanical parameters. The bearing capacity of grains has always been concerned by scholars. Sun et al. ${ }^{[5]}$, who studied the law of the effect of compression azimuth on the compression mechanical behavior of grains under different water content, pointed out that with the increase of water content, the yield load and apparent elastic modulus of millet would decrease. Thus, it can be seen that moisture content is an important index that affects the compressive performance of grain. In addition, Yang et al. ${ }^{[6]}$ used Hertz theory to analyze the results of grain stress resistance test by texture analyzer, and it was found that the elastic modulus and allowable compression stress decreased linearly. Chen et al. ${ }^{[7]}$ analyzed the tensile properties of grains from the perspective of grain structure, pointing out that the wide range of the tensile properties of grains can be attributed to the size and orientation of the fibers of grains. Liang et al. ${ }^{[8]}$ established a simulation model of grain structure based on the physical properties of grain particles, and then analyzed the influence of physical quantities such as particle shape, size and impact angle on the normal contact angle. There are many researches on the model of grain structure size and elasticity for the compressive strength of grains, but there are no specific quantitative evaluation methods and measurement indexes 
for grain damage. Wang et al. ${ }^{[9]}$ and Tang et al. ${ }^{[10]}$ studied the failure mode of rice stem microstructure under different loading forces, and obtained the characteristics of rice stem microstructure change under threshing force. Although many scholars have conducted research on the mechanical properties of grains and stalks, they have not combined the threshing force suffered during rice threshing to further study the internal damage of grains.

How to evaluate the damage caused by the impact of threshing force on the grain during rice threshing has been the focus of many scholars. Kumar et al. ${ }^{[11]}$ studied the threshing performance of grains at different drum speeds and feeding amounts, as well as the crushing rate of grains after threshing. Puauskas et al. ${ }^{[12]}$ designed a variable-radius concave surface with a $45^{\circ}$ inclination angle of the working plane as the threshing unit by taking the removal rate and the crushing rate of grains as indicators. In the same case, $\mathrm{Xu}$ et al. ${ }^{[13]}$ and Wang et al. ${ }^{[14]}$ took the crush rate, stripping rate and impurity rate observed and counted by human eyes as the main indexes of grain damage, and searched for the optimal parameter combination of threshing performance under the orthogonal test. According to the existing research results, the threshing damage of rice mainly includes internal damage and external damage, and the crack damage inside the grain is not easy to be detected and quantified. Therefore, in the design of threshing device and the evaluation of threshing performance, the detection and measurement of damage degree inside grain after threshing should not be neglected. Buerano et al. ${ }^{[15]}$ developed a percussive free fall device that can distinguish undamaged rice grains from the damaged by frequency. Hasseldine et al. ${ }^{[16]}$, by combining finite element simulation, microstructural details and the overall mechanical response of biological composite materials pointed out that the seams of the outer skin of grain played an important role in responding to external compression and transferring and distributing loads. However, none of the above studies has quantitatively analyzed the internal damage caused by the threshing process.

Micro-CT scanning technology is mostly used for research in the fields of medicine, biology, geology, etc ${ }^{[17,18]}$. Micro-CT scanning technology can obtain internal structural characteristics without damaging the external structure. Du et al. ${ }^{[19]}$ expounded the future prospects of X-ray CT technology and pointed out that CT technology is essential for the quality evaluation of agricultural products. Cantre et al. ${ }^{[20]}$ and Ambaw et al. ${ }^{[21]}$ successively applied CT technology to the research on the peel of kiwis and pomegranates. Prawiranto et al. ${ }^{[22]}$ used X-ray microcomputer tomography to quantify the physical parameters of thin-walled apple tissue under various convective drying conditions. However, there are few studies on the quantitative analysis of internal crack damage of cereal grains using Micro-CT technology or other effective methods, and the technology of applying Micro-CT scanning technology to evaluate and measure the damage of rice grains after threshing is not mature enough. In summary, there are still few studies on the quantitative internal damage of rice grains caused by threshing. Some studies have ignored the impact of the physical and mechanical characteristics of the grains on the threshing performance when carrying out research on collision damage during the threshing process of rice. The external damage model of grain also lacks a quantitative evaluation method and index for the internal damage of the grains by threshing force.

In this study, the static compression and tensile tests of rice heads and grains were conducted. The Hertz theory was used to analyze the relationship between the critical impact force and velocity of plastic deformation and brittle fracture of rice grains. The Micro-CT scanner was used to extract and calculate the internal damage area of the grain, and a quantitative evaluation model of internal damage of rice grain was established. The damage degree of the internal damage of the test machine under different loading times and loading forces was analyzed. Through the comparative analysis of the threshing force of the bars collected during the threshing process, the connection force between grains and stalks, the critical deformation force of the grain, and the bearing capacity of different degrees of damage inside the grain, the threshing performance of the existing threshing device was analyzed comprehensively.

\section{Materials and methods}

\subsection{Rice structure and three-dimensional grain size}

The research object of this study was Zhendao 11\#, an early-maturing late-late japonica rice plant grown in Zhenjiang City, Jiangsu Province, China. Rice was planted in fields with a row spacing of $200 \mathrm{~mm}$ and a plant spacing of $150 \mathrm{~mm}$. The average height of rice is about $850 \mathrm{~mm}$. The rice grains used in this test are mature. The connection force studied is at the junction of the grain and the stalk, and its direction is parallel to the stalk. The remaining mechanical properties and threshing performance of the grain are obtained by applying a load on the outside of the grain to study its deformation or damage. Their structure is shown in Figure 1.

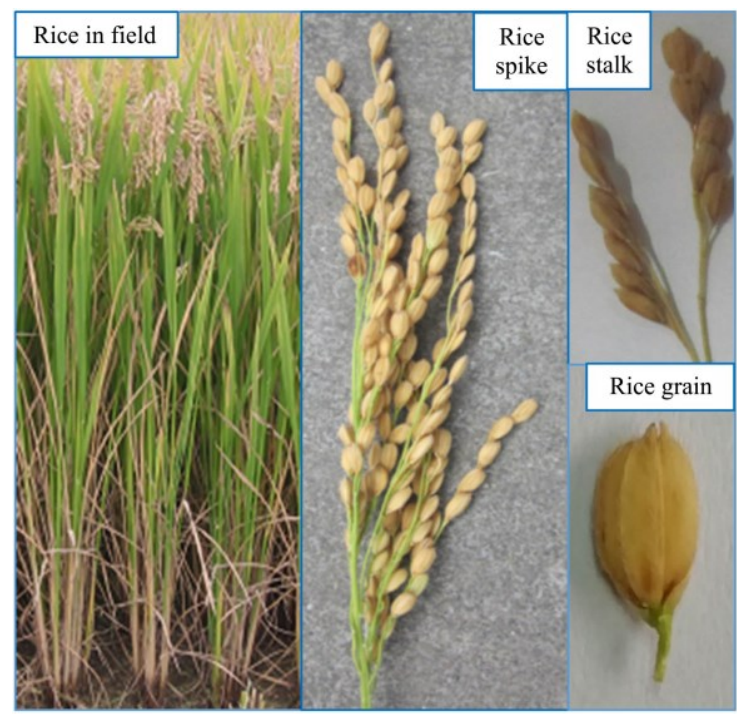

Figure 1 Panicle and grain structure of experimental rice

The shape of rice grains can generally be expressed in three dimensions: length, width, and thickness. Generally, the length is defined as the distance from the bottom to the top of the grain, the distance between the sides of the grain is the grain width, and the distance between the abdomen and the back is the grain thickness. The rice grain parameter measurement procedure is as follows: the rice was taken out $24 \mathrm{~h}$ before the test, and the room temperature was equilibrated. Grains on different rice ears were selected for threshing and mixed, and 100 grains were randomly selected for measurement with a vernier caliper and then the values were averaged. The 1000-kernel weight was measured using a BT125D electronic balance with a sample size of 10 . The results of the measurement parameters of rice grains are shown in Table 1. 
Table 1 Results of three dimensional measurements of rice grains

\begin{tabular}{ccccc}
\hline Parameter & $\begin{array}{c}\text { Length } \\
/ \mathrm{mm}\end{array}$ & $\begin{array}{c}\text { Width } \\
/ \mathrm{mm}\end{array}$ & $\begin{array}{c}\text { Thickness } \\
/ \mathrm{mm}\end{array}$ & $\begin{array}{c}\text { 1000-grain } \\
\text { weight/g }\end{array}$ \\
\hline Range of measured values & $11.88-14.94$ & $6.42-7.48$ & $4.68-5.78$ & $20.3-28.6$ \\
Mean of measured values & 6.21 & 3.47 & 2.64 & 26.4 \\
\hline
\end{tabular}

\subsection{Methods for mechanical properties of rice grains}

(1) Testing of mechanical properties of rice grains

The damage degree of rice grains after threshing depends on the relationship between the force and counterforce. The tension and pressure of the rice during threshing are the main factors that cause damage to the grains. In order to obtain the complete mechanical characteristics of rice grains during threshing, the tensile and compression tests were performed on rice with the Edberg 0824 push-pull testing machine (Precision Instrument Co., Ltd., Xindeya, Shenzhen, China) shown in Figure 2.

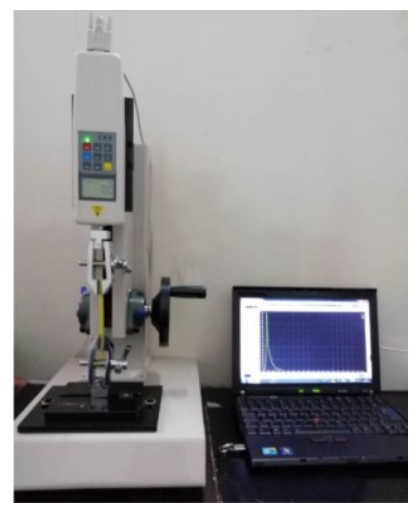

Figure 2 Composition of the push-pull testing equipment

The machine's test analysis software displays real-time tensile and pressure data and exports it for post-processing. The specific parameters of Edberg 0824 push-pull testing machine are shown in Table 2.

Table 2 Parameters of Edberg 0824 push-pull testing machine

\begin{tabular}{lc}
\hline \multicolumn{1}{c}{ Parameter Type } & Parameter value/unit \\
\hline Model & HP-200 \\
Test distance accuracy & $0.1 \mathrm{~mm}$ \\
Test force accuracy & $0.5 \%$ \\
Sensors & Built-in pressure sensor \\
Test distance range & $0.1-180.0 \mathrm{~mm}$ \\
Push-pull force range & $0-1000 \mathrm{~N}$ \\
PC interface & $\mathrm{RS} 232 \mathrm{C}$ standard port or USB port \\
Operating temperature & $-20^{\circ} \mathrm{C}-60^{\circ} \mathrm{C}$ \\
\hline
\end{tabular}

The connecting force between the grain and the stalk is an important factor to measure the degree of easiness of threshing ${ }^{[23]}$. Whether the grain has plastic deformation or brittle fracture is mainly related to the mechanical properties of the grain, such as elastic modulus, yield stress, Poisson's ratio, etc. And it is also related to the external forces on the grain. Then, the mechanical properties of rice grains can be divided into tensile and compression tests. The moving speed of the fixture is $2.5 \mathrm{~mm} / \mathrm{s}$ and the maximum stroke is $10 \mathrm{~mm}$.

During the threshing process, the grains fall off the ear of rice. Therefore, it is also necessary to use different branches of rice for tensile testing to test the connection force between rice grains and stalks, which is shown in Figure 3a. As the threshing element is working, the grains are usually under three pressure conditions: positive pressure (extrusion in the thickness direction), lateral pressure (extrusion in the width direction), and vertical pressure (extrusion in the length direction). Therefore, three independent experiments were carried out when studying the compression characteristics of rice grains. The compression situation under three-dimensional modeling is shown in Figure 3c.

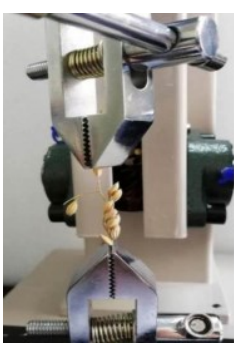
of rice grain and stalk a. Stretching method

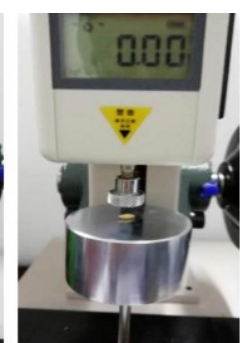

b. Method of rice grain compression

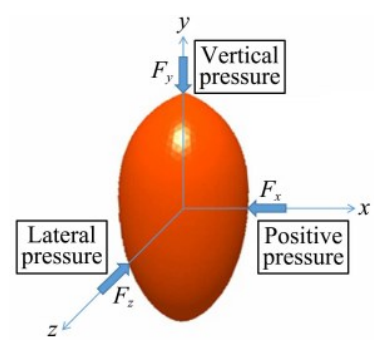

c. Three pressure conditions of grain compression
Figure 3 Model and methods of rice grain tensile and compression test

The main steps of the test for the tensile mechanical properties of rice grains are as follows: firstly, the upper and lower ends of a single rice grain ear are clamped with a fixture, and then the push-pull machine was calibrated and zeroed with a loading rate of $2.5 \mathrm{~mm} / \mathrm{s}$. Finally, a tensile force is applied to the sample and the test data are obtained, as shown in Figure 3a. The main steps of testing the mechanical characteristics of rice grain extrusion are as follows: first, raise the machine indenter to about 1.5-2 grain width, then place the grains in the middle of the machine base according to three pressure conditions, and adjust the indenter speed to $2.5 \mathrm{~mm} / \mathrm{s}$, finally start the machine to apply the load, and at the same time observe the pressure-displacement curve on the display of the instrument, and stop the test after the curve exceeds the grain yield phase.

(2) Analysis of mechanical properties of rice grains

Rice can be approximated as a uniform isotropic body. Under static loading, the elastic deformation of the grain is much smaller than the size of the grain. Therefore, the stress and deformation of the grain basically meet the assumptions of the Hertzian theory ${ }^{[24]}$. In the test, the radius of the indenter and the stage were much larger than the size of the grain, so it can be considered that the grain was squeezed by two parallel steel plates. According to Hertz theory, any two objects making elastic contact ${ }^{[25]}$ follow Equation (1):

$$
\frac{1}{E^{*}}=\frac{1-\mu_{1}^{2}}{E_{1}}+\frac{1-\mu_{2}^{2}}{E_{2}}
$$

where, $E^{*}$ is the system's comprehensive elastic constant, MPa; $E_{1}$, $E_{2}$ are the elastic modulus of rice grains and steel plate, $\mathrm{MPa} ; \mu_{1}, \mu_{2}$ are the Poisson's ratio of rice grains and steel plate.

Because the elastic modulus of the grain is much smaller than that of the steel sheet, then

$$
E^{*}=\frac{E_{1}}{1-\mu_{1}^{2}}
$$

Let the main curvature radius of rice grains at the contact point be $R_{1}$ (minimum) and $R_{1}^{\prime}$ (maximum), the main curvature radius of steel plate be $R_{2}$ (minimum) and $R_{2}^{\prime}$ (maximum), the total contact pressure is $F(\mathrm{~N})$, and the contact ellipse area be $S\left(\mathrm{~mm}^{2}\right)$. According to Hertz theory, the contact area size $S$ is determined as follows:

$$
S=2 \pi m n\left(\frac{3 F}{2 E^{*}\left(\frac{1}{R_{1}}+\frac{1}{R_{1}^{\prime}}\right)}\right)^{\frac{2}{3}}
$$

where, $m$ and $n$ are coefficients that depend on the main curvature 
radius at the point of contact between two objects.

The shape of the rice grain is similar to an ellipsoid, and the length, width, and thickness are set as $L, B$, and $H$, mm. The upper and lower ends of the grain in the thickness direction are squeezed by two parallel rigid flat plates. The main curvature radius of the contact point is expressed as follows.

$$
\begin{aligned}
& R_{1}=\frac{B^{2}}{2 H} \\
& R_{1}^{\prime}=\frac{L^{2}}{2 H} \\
& R_{2}=\infty \\
& R_{2}^{\prime}=\infty
\end{aligned}
$$

According to Hertz theory:

$$
\cos \varphi=\frac{\frac{1}{R_{1}}-\frac{1}{R_{1}^{\prime}}}{\frac{1}{R_{1}}+\frac{1}{R_{1}^{\prime}}}
$$

where, $\varphi$ is the angle between the rice grains and the main curvature plane of the steel plate, $\left({ }^{\circ}\right)$.

Substituting Equation (4) into Equation (5) can get

$$
\cos \varphi=\frac{L^{2}-B^{2}}{L^{2}+B^{2}}
$$

where, the grain sizes $B$ and $L$ were measured in the experiments, and the relevant Equation found in the references was as follows $^{[26]}$ :

$$
\begin{gathered}
m=1.939 e^{-5.26 \varphi}+1.78 e^{-1.09 \varphi}+\frac{0.723}{\varphi}+0.221 \\
n=35.228 e^{-0.98 \varphi}-32.424 e^{-1.0475 \varphi}+1.486 \varphi-2.634 \\
K=2 \lambda\left(2 \pi^{2}\right)^{1 / 3} / 3 \\
\lambda=-0.214 e^{-4.95 \varphi}-0.179 \varphi^{2}+0.555 \varphi+0.319
\end{gathered}
$$

where, $K$ is the constant determined by the main curvature radius of contact; $\lambda$ is an intermediate parameter used for empirical formula calculation.

The parameters: $\varphi, m, n, \lambda, K$ can be calculated by using $B$ and $L$ measured in the experiment according to Equations (6)-(10). According to the definition of elastic modulus,

$$
E_{1}=\frac{F H}{Q S}
$$

where, $Q$ is the grain deformation in the height direction under pressure, $\mathrm{mm}$.

Since the loading platform is fixed and the small deformation and contact state of grains due to compression are symmetrical, the displacement of the steel plate is 2 times of the compression deformation of rice grains. According to Hertz theory, then,

$$
Q=K\left[\frac{9 F^{2}\left(\frac{1}{R_{1}}+\frac{1}{R_{1}^{\prime}}+\frac{1}{R_{2}}+\frac{1}{R_{2}^{\prime}}\right)}{\pi^{2} E^{* 2}}\right]^{\frac{1}{3}}=K\left[\frac{18 H F^{2}\left(1-\mu_{1}^{2}\right)^{2}\left(B^{2}+L^{2}\right)}{\pi^{2} B^{2} E_{1}^{2} L^{2}}\right]^{\frac{1}{3}}
$$

Therefore, the contact pressure Equation of grains is as follows,

$$
F=\frac{\pi E^{*} Q^{3 / 2}}{3 K^{3 / 2}\left(\frac{1}{R_{1}}+\frac{1}{R_{1}^{\prime}}\right)^{1 / 2}}=\frac{\pi E_{1} Q^{3 / 2} B L}{3\left(1-\mu_{1}^{2}\right) \sqrt{2 H K^{3}\left(B^{2}+L^{2}\right)}}
$$

Substitute Equation (13) into Equation (3) to obtain

$$
S=\frac{2^{-1 / 3} \pi^{5 / 3} Q B^{2} L^{2} m n}{K H\left(B^{2}+L^{2}\right)}
$$

(3) Theoretical analysis of rice grain impact damage

The moisture content of rice grains is generally between $16 \%$ and $25 \%$ when harvesting. When the moisture content is higher than $25 \%$, it can be regarded as plastic material approximately. When the moisture content is less than $16 \%$, it can be regarded as a type of brittle material. The threshing bar and the grain deform elastically at the beginning of the impact, which can be recovered after unloading. In this process, the relationship among deformation, contact pressure and impact force can be calculated through contact mechanics. When the maximum contact pressure exceeds the yield limit, plastic deformation will occur. The brittle fracture occurs when the strength limit is exceeded. Since plastic deformation and brittle fracture should be avoided, we studied the critical impact force and linear velocity of threshing bar when plastic deformation and brittle fracture occurred respectively in rice grains.

According to Hertz theory, when two objects in general shape are in contact, the contact area, the compression deformation and the maximum pressure on the contact surface are as follows, respectively ${ }^{[27]}$

$$
\begin{gathered}
c=\left(\frac{3 P_{0} R_{e}}{4 E^{*}}\right)^{\frac{1}{3}} \\
\delta=\left(\frac{9 P_{0}^{2}}{16 E^{* 2} R_{e}}\right)^{\frac{1}{3}} F_{2} \\
P_{1}=\frac{3 P_{0}}{2 \pi c^{2}} \\
R_{e}=\sqrt{R_{1} R_{1}^{\prime}}
\end{gathered}
$$

where, $c$ is the contact area size, $\mathrm{mm}^{2} ; P_{0}$ is the impact force, $\mathrm{N} ; R_{e}$ is the equivalent relative radius of curvature, $\mathrm{mm} ; \delta$ is the compression deformation, $\mathrm{mm} ; F_{2}$ is the correction factor determined by the relative curvature ratio; $P_{1}$ Maximum contact pressure, $\mathrm{N}$.

The relative velocity of threshing bar and rice grain is:

$$
v_{2}(t)-v_{1}(t)=\frac{\mathrm{d} \delta}{\mathrm{d} t}
$$

where, $v_{2}(t)$ is the velocity of rice grain at time $\mathrm{t}, \mathrm{m} / \mathrm{s} ; v_{1}(t)$ is the velocity of threshing bar at time $t, \mathrm{~m} / \mathrm{s}$.

At any moment, the force between the grain and the threshing bar is $P_{0}(t)$, then

$$
P_{0}(t)=m_{1} \frac{\mathrm{d} v_{1}}{\mathrm{~d} t}=-m_{2} \frac{\mathrm{d} v_{2}}{\mathrm{~d} t}
$$

where, $m_{1}$ is the mass of the threshing bar, $\mathrm{g} ; m_{2}$ is the grain mass of rice, $\mathrm{g}$.

For the convenience of calculation, let $m=\frac{m_{1} m_{2}}{m_{1}+m_{2}}$, combining Equations (16), (19) and (20), then

$$
m \frac{\mathrm{d}^{2} \delta}{\mathrm{d} t^{2}}=-\frac{4}{3} R_{e}^{\frac{1}{2}} E^{*} F_{2}^{-\frac{3}{2}} \delta^{\frac{3}{2}}
$$

By integrating both sides of Equation (21), we can obtain

$$
m\left[\left(v_{2}(0)-v_{1}(0)\right)^{2}-\left(\frac{\mathrm{d} \delta}{\mathrm{d} t}\right)^{2}\right]=\frac{16}{15} R_{e}^{\frac{1}{2}} E^{*} F_{2}^{-\frac{3}{2}} \delta^{\frac{5}{2}}
$$

In the case of maximum compression $\delta_{\max }, \mathrm{d} \delta / \mathrm{d} t=0$, the maximum compression deformation can be calculated as follows according to Equation (22),

$$
\delta_{\max }=\left(\frac{15 m\left(v_{2}(0)-v_{1}(0)\right)^{2} F_{2}^{\frac{3}{2}}}{16 R_{e}^{\frac{1}{2}} E^{*}}\right)^{\frac{2}{5}}
$$

Combining Equations (16), (17), and (23), the relationship between the maximum contact pressure and the relative speed at this time is as follows: 


$$
P_{1 \max }=\frac{3}{2 \pi}\left(\frac{5}{4} m\left(v_{2}(0)-v_{1}(0)\right)^{2}\right)^{\frac{1}{5}}\left(\frac{4 E^{*}}{3 R_{e}^{\frac{3}{4}} F_{2}^{\frac{1}{4}}}\right)^{\frac{4}{5}}
$$

The relationship between the critical impact force and the maximum contact pressure obtained by combining Equations (15) and (16) is as follows:

$$
P_{0 \max }=\frac{\pi^{3} R_{e}^{2} P_{1 \max }^{3}}{6 E^{* 2}}
$$

Since the water content of rice grains is mostly in the range of $16 \%-25 \%$, and its mechanical properties are between plastic materials and brittle materials, which are relatively complex, the critical impact force of the two cases is analyzed as follows.

According to the von Mises rule for plastic materials ${ }^{[28]}$, at the maximum compression moment, when the contact pressure $P_{1}$ reaches $1.6 \sigma_{s}$, the point below the surface of the contact area between the grain and the threshing bar reaches the limit of the plastic state, completing the yield and forming a stress crack. Combining the critical condition with Equation (25), the critical impact force of plastic deformation is

$$
P_{s \max }=\frac{256 \pi^{3} R_{e}^{2} \sigma_{s}^{3}}{375 E^{* 2}}
$$

where, $\sigma_{s}$ is the yield stress of the grains, MPa; $P_{s \max }$ is the critical impact force with plastic deformation, $\mathrm{N}$.

Combining the critical condition with Equation (24), the relative critical speed of plastic deformation of grains and threshing bars upon impact is

$$
v_{s}=\left(106.96 \frac{\sigma_{s}^{5} R_{e}^{3} F_{2}}{m E^{* 4}}\right)^{\frac{1}{2}}
$$

where, $v_{s}$ is the relative critical speed of plastic deformation of grains and threshing bars, $\mathrm{m} / \mathrm{s}$.

At the moment of maximum compression, according to the criterion of normal stress fracture for brittle materials, under axial compression load, when the contact pressure $P_{1}$ reaches the ultimate tensile strength $\sigma_{b}$ of grains under uniaxial compression, the point under the contact area between rice grains and threshing bar reaches the limit of elastic state, forming stress crack or fragmentation.

Combined with Equation (25), the critical impact force of brittle fracture can be obtained as follows:

$$
P_{b \max }=\frac{\pi^{3} R_{e}^{2} \sigma_{b}^{3}}{6 E^{* 2}}
$$

where, $\sigma_{b}$ is the ultimate tensile strength of the grains, $\mathrm{MPa} ; P_{b \max }$ is the critical impact force of brittle fracture, $\mathrm{N}$.

In joint Equation (24), the relative critical velocity of brittle fracture occurred by impact between grain and threshing bar is

$$
v_{b}=\left(10.2 \frac{\sigma_{b}^{5} R_{e}^{3} F_{2}}{m E^{* 4}}\right)^{\frac{1}{2}}
$$

where, $v_{b}$ is the relative critical speed of brittle fracture of grains and threshing bars, $\mathrm{m} / \mathrm{s}$.

\subsection{Establishment of quantitative model of rice internal} damage based on micro stress crack

(1) Quantitative analysis of rice grain internal damage

The degree of damage is a physical quantity describing the degree of damage to a material or an object's structure. It is usually expressed by the proportion of the volume of cracks and micropores in the entire object. In this study, the damage degree is defined as the ratio of the area where stress cracks occur inside the rice grain to the total area of the rice grain slice. The Equation is expressed as:

$$
D=\frac{S_{1}}{S}
$$

where, $D$ is internal damage degree, $\% ; S_{1}$ is the crack area, $\mathrm{mm}^{2}$; $S$ is the total section area, $\mathrm{mm}^{2}$.

The gray value of the crack and the connecting part of the endosperm to the embryo under CT scanning is 0 ; the number of pixels of the connecting part of the endosperm to the embryo can be calculated by the unloaded section diagram of the grain. Therefore, Image software can be used to count the number of pixels with a gray value of 0 to obtain the area of both. Similarly, the total area of the sample can also be obtained. In the actual calculation process, Equation (30) is converted into the ratio of the pixel numbers:

$$
D=\frac{N_{1}-M}{N}
$$

where, $N_{1}$ is the sum of the number of crack pixel points and pixel points on the connecting part of endosperm and embryo on section; $M$ is the number of pixel points on the connecting part of embryo and endosperm; $N$ is the total number of pixel points on section.

(2) Extraction of microscopic stress crack

Our research team has carried out related research on rice grains with the application of Micro-CT 100 scanner system in previous studies ${ }^{[29]}$. Therefore, in this study, the same method for image analysis and feature extraction was applied to CT scans. The differences in gray values based on the non-uniform physical characteristics of rice grains were generated, and then the connection parts between endosperm and embryo and the rest of the grain are distinguished by CT imaging technology ${ }^{[30]}$. According to the bimodal threshold segmentation method, the average value of the two peaks of the CT gray frequency histogram is the optimal threshold, and the damage region is extracted from the $\mathrm{CT}$ gray image.

The image is processed by Image J v1.8.0 software, and the segmented image is processed into a binary image. There are only pure black and pure white in the image, that is, the gray value is 1 and 0 . The white is the crack damage and the junction between the embryo and the endosperm, and the black is the structure of the grain.

After the image processing above, the degree of internal damage of rice grains is transformed into

$$
D=\frac{N_{1}-M}{N}=\frac{\underset{(x, y) \in C}{f}(x, y) \leq \frac{\underset{(x, y) \in A}{f}(x, y)_{\max }+\underset{(x, y) \in B}{f}(x, y)_{\max }}{2}}{\sum_{(x, y) \in A}}
$$

where, $f(x, y)_{\max }$ is two peaks in the gray frequency histogram; $A$ is the pixel point in the binary image whose gray value is $0 ; B$ is the pixel in the background of the image; $C$ is the number of pixel points of embryo and endosperm sections when rice seeds are unloaded.

(3) Internal damage test of rice grains

After establishing the internal damage model of rice grains, the related research on the internal damage characteristics of rice grains was conducted under different loads. According to the experimental characteristics of rice extrusion mechanics, the internal damage of the grains when the same load was applied under three pressure conditions: positive pressure, lateral pressure, and vertical pressure, was analyzed. Under different pressure modes, 50-160 N load was applied to rice grains, and the interval between each test load was $10 \mathrm{~N}$. When the target load was reached, the grains were unloaded and the scanning test was carried 
out. In order to prevent pseudo-image caused by grain movement during the scanning process, the grains were installed in the sponge, and the sponge was fixed in the scanning bucket. The scanning range was the whole grain, and the section spacing was $0.01 \mathrm{~mm}$.

The direct factors affecting threshing damage include the number of hits and the value of the external strike force ${ }^{[31]}$. Therefore, we selected undamaged rice grains for the extrusion test to further study the relationship between rice grain damage and loading times. Considering the experimental condition, the minimum number of loading times is set to 2 times, the maximum is 6 times, and the loading times interval is 2 times. The minimum loading force is $50 \mathrm{~N}$, the maximum is $160 \mathrm{~N}$, and the loading interval is $10 \mathrm{~N}$. After the experiment, Micro-CT was used for scanning, and the quantitative characterization method of internal damage in this study was used for internal damage calculation. The functional relationship and 3D surface diagram of internal damage degree, loading times, and applied load were obtained by fitting the test data with the Matlab function based on the least square method.

\subsection{Threshing force test of drum}

In order to analyze and evaluate the effective threshing efficiency and damage degree of the existing threshing drum to rice grains, the force on the rice grains during the threshing process needs to be measured and the structure damage mode of the rice grains after threshing needs to be found out. The rice threshing experiment was carried out with the axial nail-tooth threshing cylinder with a diameter of $580 \mathrm{~mm}$, length of $1360 \mathrm{~mm}$, and a test speed of $550 \mathrm{r} / \mathrm{min}$.

In order to truly and accurately reflect the changes in the force of rice during the threshing process and generate dynamic threshing

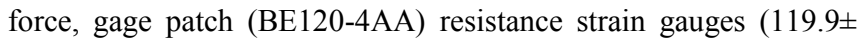
0.1) $\Omega$ and MF-G14 silicone adhesive were used. In this experiment, the strain gauge was arranged at the main stress position of the threshing drum's nail-teeth during the work, and the data of stress changes collected by the data acquisition card was imported into the computer software for real-time display, so as to measure the stress range of rice during the threshing process. The distance between the four strain gauge placement positions and the supporting plate at the left end of the drum is $260 \mathrm{~mm}, 500 \mathrm{~mm}$, $735 \mathrm{~mm}$ and $975 \mathrm{~mm}$, respectively. The actual position and the roller model are shown in Figure 4a.

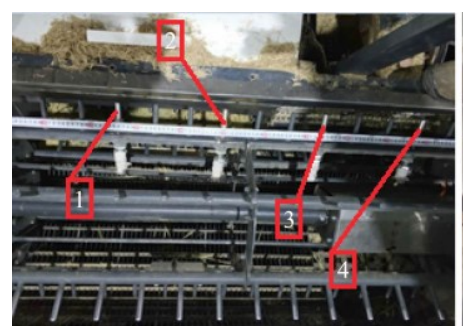

a. Threshing force test method

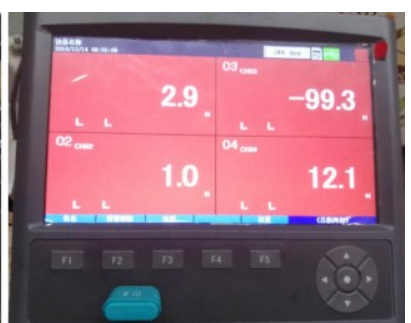

b. Real-time data display of threshing force
Note: 1, 2, 3, 4 in Figure 4a are strain gauges 1-4.

Figure 4 Test of threshing force during rice grains threshing

After feeding the rice into the drum, the rice panicle head was mainly impacted by the mutual extrusion of the threshing drum nail teeth and the concave plate sieve, as well as the tension and extrusion between the nail teeth and the rice. The strain gauge signal from the threshing bar is first transmitted to the signal acquisition system and then wirelessly transmitted to an external computer receiver to display the collected signal in real-time. At the end of the experiment, the rice grains were classified, and the damage characteristics were observed and photographed. The data collected by the software is exported for further analysis.

\section{Results and discussion}

\subsection{Mechanical characteristics of rice grains}

(1) Processing and analysis of static tension and extrusion test data

By analyzing the two-point tensile test of rice grains and grain stalks, it was found that only one peak appeared at the two-point stretching, and then the load force quickly decreased to 0 . The results of the rice grain tensile test are shown in Figure 5.

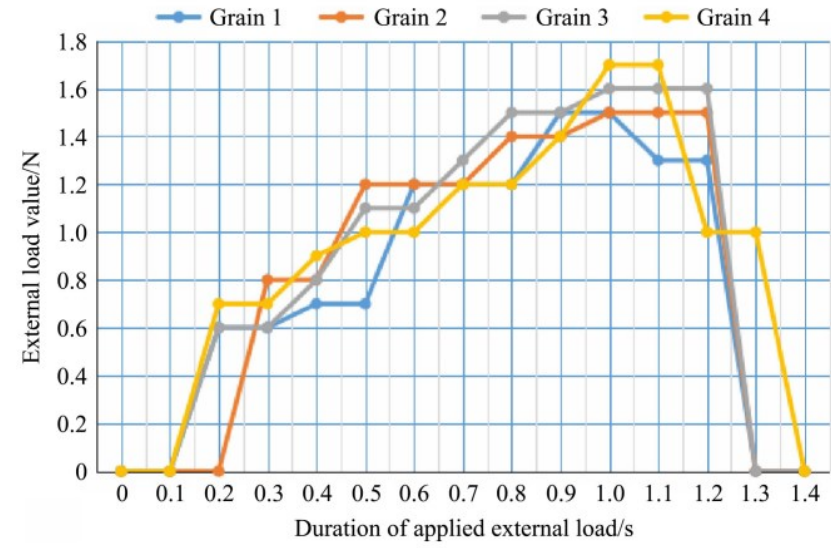

Figure 5 Broken line of connecting force between grain and stalk in tensile test

As shown in Figure 5, the unique peak in the broken line diagram is the connection force between the rice grain and its stalk. After the fracture, the load value is 0 because the grain is separated from the stalk. The two-point tension rupture of grain and stalk is characterized by the separation of them. The load peak range of all samples is $1.40-1.70 \mathrm{~N}$, the mean is $1.57 \mathrm{~N}$, and the variance is 0.0529 .

The experimental data under three pressure conditions of rice grains: positive pressure, lateral pressure and vertical pressure was smoothed by Matlab. Their mechanical characteristic curves are shown in Figure 6.

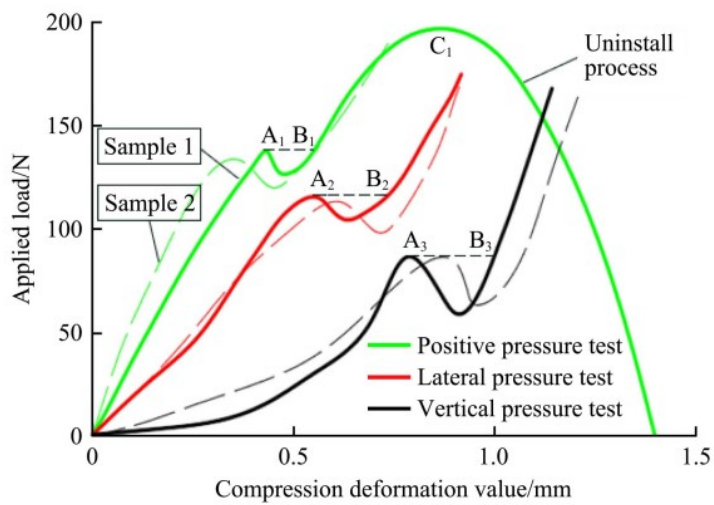

Note: $A_{1}, A_{2}, A_{3}$ are the breaking points of the grains under positive pressure, lateral pressure and vertical pressure; $B_{1}, B_{2}$, and $B_{3}$ are the points of the end of the yield phase under positive pressure, lateral pressure and vertical pressure; $\mathrm{C}_{1}$ is the starting point of unloading process.

Figure 6 Deformation curve of rice grains under three pressure conditions

The curve can be divided into $\mathrm{OA}, \mathrm{AB}$ and $\mathrm{BC}$ sections. When the load approaches point $\mathrm{A}$, cracks begin to appear. The damage and failure of grains in OA section are mainly manifested by the generation and expansion of cracks along the short axis. The grain begins to break at point $\mathrm{A}$, so the force at point $\mathrm{A}$ is its 
destructive force. $\mathrm{AB}$ segment is the yield phase, where the curve drops or flattens, and the grains begin to break. The grains in the $\mathrm{BC}$ segment are gradually compressed, the cracks are gradually deepened and widened, and the endosperm becomes powdery. With the increase of load in this segment, the grain deformation becomes smaller and smaller. After point $\mathrm{C}$ is the unloading process, the load rapidly decreases to 0 .

As shown in Figure 6, the extrusion force-deformation curves of rice grains under three pressure conditions have the same trend, including a peak point and yield stage. When a certain load is applied, cracks are formed in the grains, and as the cracks continue to expand, the grains are broken at the peak point.

The 10 independent tests were conducted for each loading method. After the $k$-means clustering analysis based on the least square method, the rice grain damage and the clustering center point of shape variables under each loading method could be obtained. The clustering analysis diagram is shown in Figure 7 could be obtained through Matlab, and the data are shown in Table 3.

Table 3 Extrusion mechanical properties of three pressure conditions

\begin{tabular}{lccc}
\hline \multicolumn{1}{c}{ Pressure condition } & $\begin{array}{c}\text { Positive } \\
\text { pressure/N }\end{array}$ & $\begin{array}{c}\text { Lateral } \\
\text { pressure/N }\end{array}$ & $\begin{array}{c}\text { Vertical } \\
\text { pressure/N }\end{array}$ \\
\hline Range of destructive force & $127-138$ & $108-115$ & $83-92$ \\
Range of deformation & $0.43-0.48$ & $0.53-0.60$ & $0.82-0.92$ \\
Mean of critical force & 129 & 112 & 87 \\
Mean of deformation & 0.47 & 0.57 & 0.85 \\
Cluster center & $(0.46,132)$ & $(0.56,111)$ & $(0.87,86)$ \\
\hline
\end{tabular}

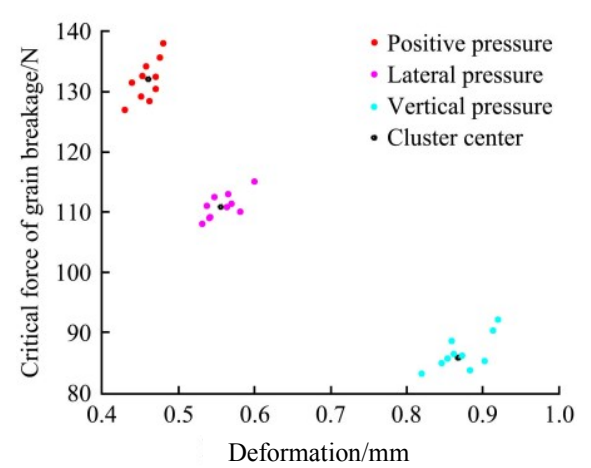

Figure 7 -means cluster analysis diagram of rice grain destructive force

It can be clearly seen from Figure 7 that the test data is effectively divided into three categories by $k$-means, and the destructive force under each loading method is different. It can be seen from the figure that the destructive force under positive pressure is greater than destructive force under lateral pressure while destructive force under lateral pressure is greater than destructive force under vertical pressure. However, the deformation of the grains under each loading method was different when they reached breaking point A. It can be seen from Figure 7 that when the destructive force is reached, the magnitude of the deformation caused by three pressure conditions is ranked in order as vertical pressure, lateral pressure, positive pressure.

(3) Calculation of mechanical characteristic parameters of rice grains

The threshing element of the test analysis object is the nail tooth. The material is $\mathrm{Q} 235 \mathrm{~A}$, the elastic modulus $E_{2}=2.06 \times$ $10^{5} \mathrm{MPa}$, Poisson's ratio $\mu_{2}=0.28$, and the diameter $\Phi=16 \mathrm{~mm}$. The average values of the triaxial dimensions of the rice grains were $L=6.21 \mathrm{~mm}, B=3.47 \mathrm{~mm}$, and $H=2.64 \mathrm{~mm}$. According to $\mathrm{Xu}$ et al. ${ }^{[32]}$, determined the Poisson's ratio of rice grains $\mu_{1}=0.386$, the yield stress of the grains $\sigma_{s}=36.40 \mathrm{MPa}$, the ultimate tensile strength of the grains $\sigma_{b}=59.20 \mathrm{MPa}$.

Substituting the triaxial size of rice grains into Equation (4) and Equation (18), the relevant parameters are as follows:

$$
R_{1}=2.280, R_{1}^{\prime}=7.305, R_{e}=4.081
$$

Substituting the triaxial size of rice grains into Equations (7)-(10), the relevant parameters are as follows:

$$
\varphi=1.019, m=1.526, n=0.707, K=1.256, \lambda=0.697
$$

It can be seen from Equation (13) that in the elastic deformation stage of rice grains, the static load compression force $F$ has a linear relationship with the displacement $Q^{1.5}$ of rice grains. Therefore, the linear fitting of $F$ and $Q^{1.5}$ in the elastic deformation stage is conducted based on the least square method and the elastic modulus $E_{1}=298.32 \mathrm{MPa}$ of rice grains is obtained by combining the relevant parameters that have been calculated.

The combined elastic modulus of the threshing bar and rice grains $E^{*}=350.00 \mathrm{MPa}$ according to Equation (1).

Because the mass of threshing bar is much larger than that of grain mass, according to the relative curvature ratio $\left(\frac{R_{1} R_{2}}{R_{1}+R_{2}} \cdot \frac{R_{1}^{\prime}+R_{2}^{\prime}}{R_{1}^{\prime} R_{2}^{\prime}}\right)^{\frac{1}{2}}=0.312, F_{2}=1.0$ can be obtained.

Substituting the above data into Equations (26)-(29), it can be concluded that when the rice grain presents plastic deformation and brittle fracture respectively, the critical impact force and borderline velocity of the threshing bar are plastic deformation: $P_{\text {smax }}=$ $138.79 \mathrm{~N}, v_{s}=34.24 \mathrm{~m} / \mathrm{s}$; brittle fracture: $P_{b \max }=145.77 \mathrm{~N}, v_{b}=$ $35.67 \mathrm{~m} / \mathrm{s}$.

From the above results, if the physical parameters of rice grains are not considered (because they are difficult to control by humans), the relative movement speed and critical impact force of the rice grains when they collide with the threshing bar without plastic deformation and brittle fracture are mainly related to the elastic modulus of threshing element, the maximum and minimum radius of curvature where the rice grains contact the threshing bar.

\subsection{Quantitative model of rice internal damage}

(1) Effect of compression mode on internal damage

In order to comprehensively evaluate the advantages and disadvantages of existing threshing bars for rice grain threshing, the tests of the internal damage of rice grains under different loading modes and different external forces were needed. The final treatment results of Micro-CT scans of some test samples obtained through the evaluation methods and tests of internal grain damage are shown in Figure 8.

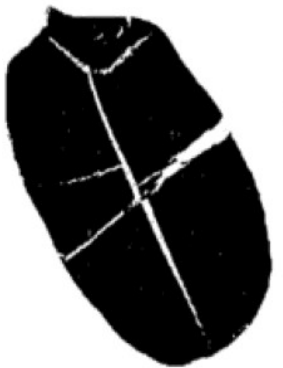

a. Positive pressure load b. Lateral pressure load of c. Vertical pressure load of of $160 \mathrm{~N}$

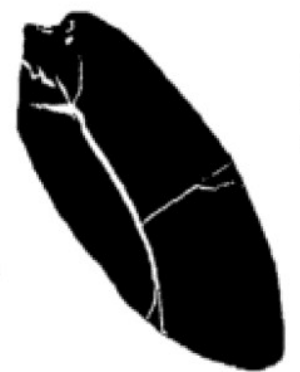

$130 \mathrm{~N}$

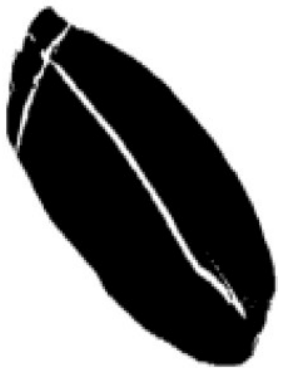

$110 \mathrm{~N}$
Figure 8 Binary image of CT scan

The relation curves of load and damage degree under different pressure conditions are shown in Figure 9 and Table 4. 
Table 4 Internal damage degree (\%) under different loads in three pressure conditions

\begin{tabular}{|c|c|c|c|c|c|c|c|c|c|c|c|c|}
\hline \multirow{2}{*}{$\begin{array}{l}\text { Pressure } \\
\text { conditions }\end{array}$} & \multicolumn{12}{|c|}{ External force/N } \\
\hline & 50 & 60 & 70 & 80 & 90 & 100 & 110 & 120 & 130 & 140 & 150 & 160 \\
\hline Positive pressure & 0 & 0 & 0 & 0 & 0 & 0.52 & 0.84 & 1.34 & 1.98 & 2.73 & 2.85 & 5.52 \\
\hline Lateral pressure & 0 & 0 & 0 & 0 & 0.60 & 1.78 & 2.83 & 3.08 & 4.26 & 7.18 & 12.63 & 15.00 \\
\hline Vertical pressure & 0 & 0.01 & 1.62 & 1.78 & 2.85 & 3.67 & 4.06 & 6.07 & 8.83 & 11.96 & 15.00 & 15.00 \\
\hline
\end{tabular}

It can be seen from Figure 9 and Table 4 that under different loading modes, the damage degree increases gradually with the increase of external force. Additionally, the increased rate of damage degree per unit is small at the early stage of loading and then increases with the increase of load until the grain is broken.

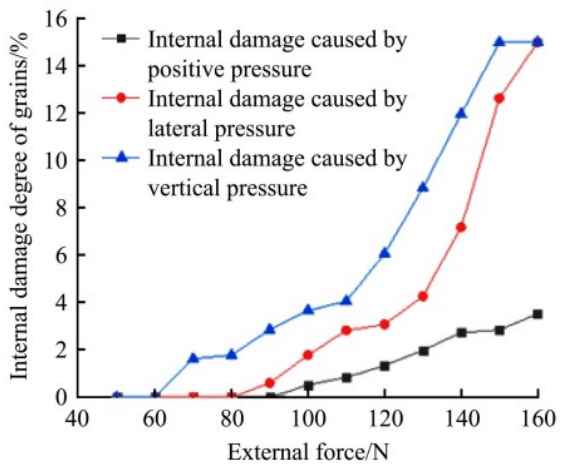

Figure 9 Relationship between load and internal damage under different loading modes

Because the destructive force of rice grains under different pressure conditions is different, the critical force is different when damage occurs. From Figure 9, it can be seen that the relationship between the external force when the grains are damaged under three pressure conditions is that positive pressure is greater than lateral pressure while lateral pressure is greater than vertical pressure. It can be seen from the figure that the internal damage degree of the same load under three pressure conditions is: vertical pressure $>$ lateral pressure $>$ positive pressure. Under the same load, the grains under the vertical pressure appear crack damage first, and the damage is the most serious. This is consistent with the results of Section 3.1 (1) static load extrusion test.

(2) Quantitative relationship of three variables: loading times, external force and internal damage degree

In this experiment, as the external force increased and the loading times increased, rice grains were broken. This paper analyzed the broken grains through the internal damage degree model established above, and found that the general critical internal damage degree of broken rice grains was about $15 \%$. Therefore, the internal damage degree of broken rice grains was uniformly defined as $15 \%$. The test scheme and results are shown in Table 5.

Table 5 Internal damage degree (\%) of rice grains by multiple loadings and different external forces

\begin{tabular}{cccccccccc}
\hline \multirow{2}{*}{$\begin{array}{c}\text { Loading } \\
\text { times }\end{array}$} & 80 & 90 & 100 & 110 & 120 & 130 & 140 & 150 & 160 \\
\cline { 2 - 9 } & 0 & 0 & 0.15 & 0.56 & 1.52 & 2.11 & 2.90 & 6.62 & 7.87 \\
\hline 2 & 0 & 0.16 & 1.01 & 1.30 & 3.49 & 5.43 & 5.76 & 9.27 & 15 \\
4 & 0.53 & 1.42 & 2.24 & 3.87 & 8.24 & 15 & 15 & 15 & 15 \\
6 &
\end{tabular}

In order to study the influence of loading times and external force on internal damage degree, we carried out $z$-score standardization processing on loading times $C$ and external force $F$ to eliminate the dimensional influence between indexes ${ }^{[33]}$. The equation is as follows:

$$
x^{*}=\frac{x-\mu}{\sigma}
$$

where, $x^{*}$ is the normalized data; $x$ is the original data; $\mu$ is the mean value of the data; $\sigma$ is the data standard deviation.

Matlab curve fitting toolbox was used to perform surface fitting on the data in the table according to the main of the least square method. The surface fitting Equation obtained is as follows:

$$
\begin{aligned}
& D(C, F)=3.242+3.083 C+4.844 F+1.056 C^{2}+3.075 C F+1.139 F^{2} \\
& +0.5705 C^{2} F-0.6603 C F^{2}-0.8542 F^{3}-0.08806 C^{2} F^{2}-0.9995 C F^{3} \\
& -0.2343 F^{4}
\end{aligned}
$$

where, $D$ is the degree of internal damage, $\% ; C$ is the loading times; $F$ is the value of the external force, $\mathrm{N}$.

The surface fitting diagram drawn by Matlab is shown in Figure 10.

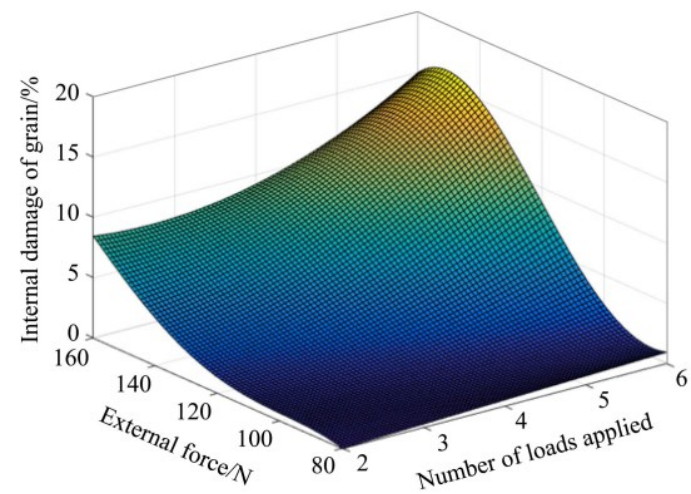

Figure 10 3D surface diagram of internal damage of grain over loading times and external force

According to the fitting analysis, the SSE (which means the sum of squares due to error) value of the fitting function is 23.65 and the RMSE (which means root mean squared error) value is 1.256. Compared with the variable value, the two values are very small, indicating that the fitting value is very close to the truth value. $\mathrm{R}^{2}$ (which means coefficient of determination) value is 0.9697 and the Adjusted $\mathrm{R}^{2}$ (which means degree-of-freedom adjusted coefficient of determination) is 0.9474 , both of which are close to 1 , indicating that the fitting of the regression function is very good and the accuracy is very high.

\subsection{Analysis of threshing force test results}

The four threshing bars are uniformly arranged on the axial nail-tooth threshing cylinder. After threshing completes, data collected by four sensors is processed ${ }^{[34,35]}$. Since the sampling frequency is $4000 \mathrm{~Hz}$ and the data volume is very large, it is necessary to conduct interval sampling of the collected signals. Representative time interval is selected for processing, and the real-time threshing force curve of the threshing process is shown in Figure 11.

As shown in Figure 11, the threshing force on the four threshing bars has obvious irregular fluctuations, and the discontinuous fluctuations of real-time threshing force are mainly caused by the discontinuity of rice feeding. Even at the same time, 
the forces of different threshing bars vary greatly. The real-time threshing forces in Figure 11 were analyzed, and the mean value of stable force, minimum effective threshing force, maximum effective threshing force, the mean value of effective threshing force and variance of effective threshing force were used as indicators to compare the data of four threshing bars, as shown in Figure 12.

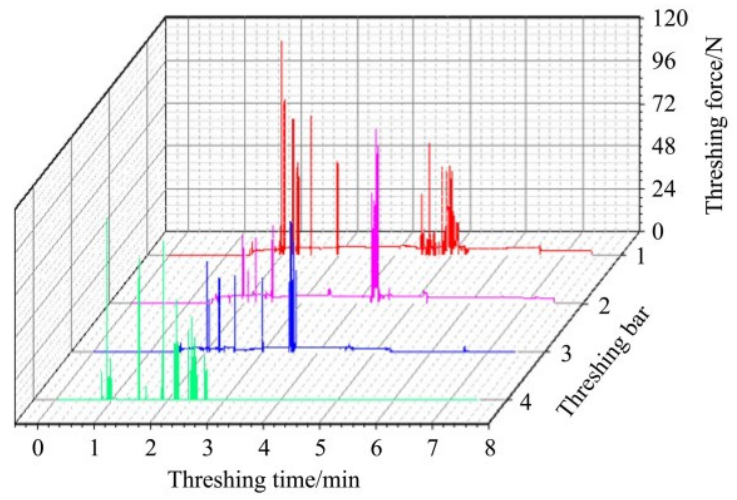

Figure 11 Threshing force waterfall diagram of four threshing bars on the roller

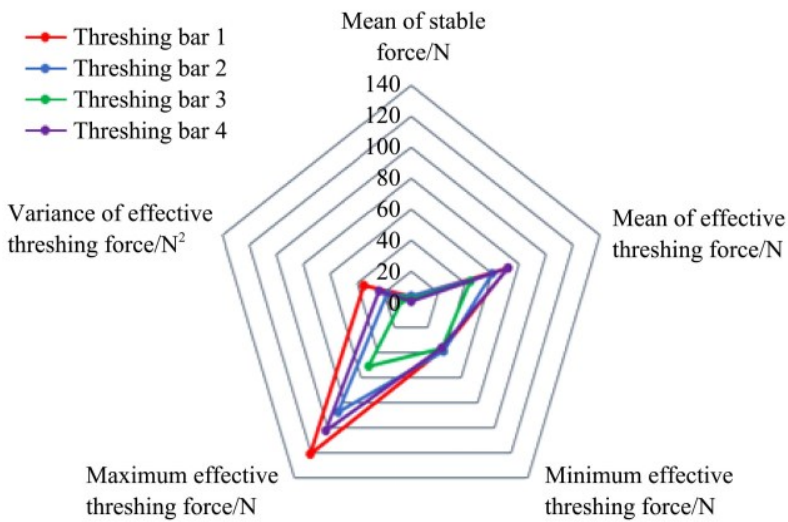

Figure 12 Radar diagram of data comparison of four threshing bars on the roller

According to the data comparison in Figure 12, it can be found that, compared with the effective threshing force, the stable threshing force on the four threshing bars is very low $(0.6-3.9 \mathrm{~N})$, which is the inertial force of the threshing bars without load. When there is a load, the force on the threshing bars is the effective threshing force. The minimum variance of effective threshing force is 6.4 of the third threshing bar, which also proves that the randomness of threshing force is significant. The minimum effective threshing force of the four threshing bars is very close (36.4-37.7 N), while the maximum effective threshing force is quite different (51-121 N). The ranking of the maximum effective threshing force is basically the same as the ranking of the variance of the effective threshing force. According to Figure 12, the mean of effective threshing force on the bar is in the range of $43.9 \mathrm{~N}$ to $71.9 \mathrm{~N}$.

\subsection{Quantitative analysis of internal damage of grain by threshing bars}

According to the surface fitting Equation (34) obtained in Section 3.2, the external forces needed to achieve $0 \%, 5 \%, 10 \%$ and $15 \%$ internal damage of rice grains under 2, 4 and 6 loads are calculated. The results are shown in Table 6 .

The data in Table 6 with the critical impact force of brittle fracture, plastic deformation and experimental threshing force of rice grains were compared and analyzed. The results are shown in
Figure 13. The load range without internal damage is defined as "safe area", and the range with more than $15 \%$ internal damage is defined as "crushing area". For the crushing area of grains, only the critical force reaching crushing state is worth studying. The whole interzone is not of research significance, so it is not shown in the figure.

Table 6 Critical load (N) of internal damage degree under different loading times

\begin{tabular}{cccc}
\hline \multirow{2}{*}{$\begin{array}{c}\text { Internal damage } \\
D / \%\end{array}$} & \multicolumn{3}{c}{ Loading times } \\
\cline { 2 - 4 } & 2 & 4 & 6 \\
\hline 0 & 105.1 & 88.2 & 84.7 \\
5 & 146.5 & 129.0 & 109.8 \\
10 & 167.2 & 158.8 & 124.3 \\
15 (crushing) & 193.8 & 162.8 & 141.3 \\
\hline
\end{tabular}

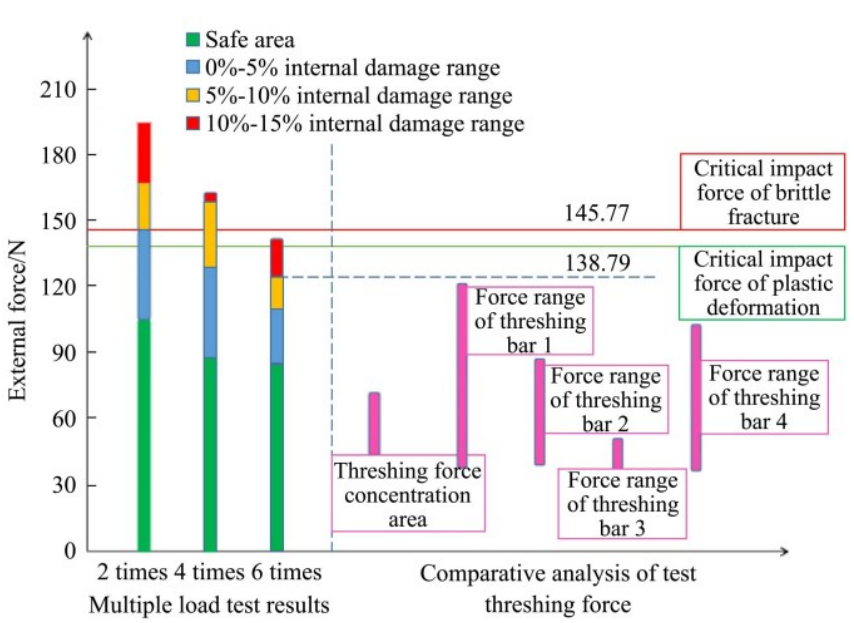

Figure 13 Damage of threshing bar to grain

As shown in Figure 13, among the four threshing bars, the first threshing bar has the largest range of variation and the peak effective threshing force. But the peak effective threshing force still does not reach the critical impact force of plastic deformation and brittle fracture. The concentrated area of threshing force on the four threshing bars is in the safe area under 2, 4 and 6 loading times. To further integrate the results of the load test and the threshing force test, they are shown in Figure 14.

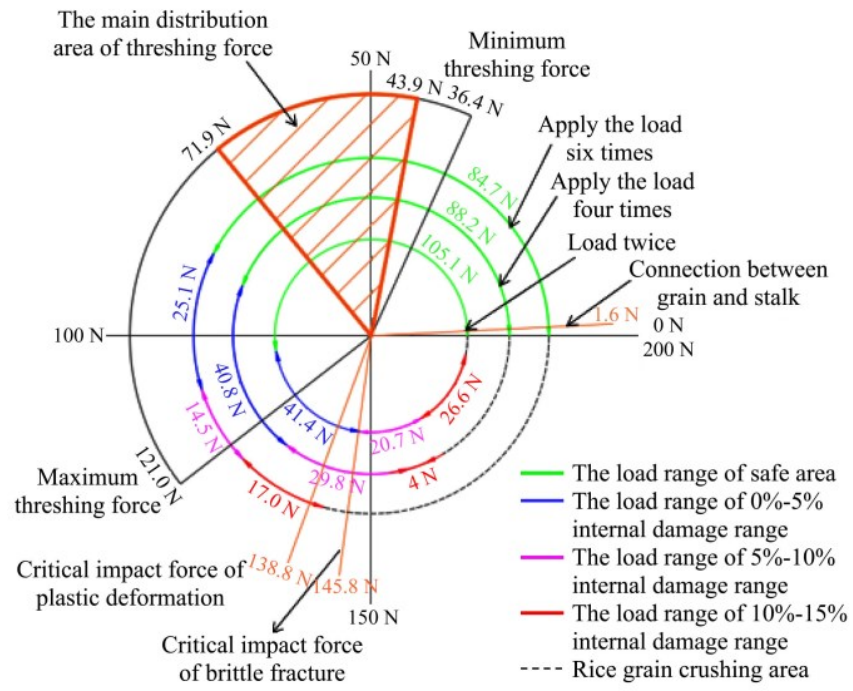

Figure 14 Comparison diagram of comprehensive analysis of internal damage of grains

From the comparative analysis of the experimental data in Figure 14, it can be seen that (1) the test threshing force did not 
reach the critical impact force required for plastic deformation or brittle fracture of rice grains, and far exceeded the connection force between the grains and the grain stalk, indicating that the force is safe and effective, and can cause the rice grains to detach without plastic deformation and brittle fracture; (2) The threshing force-intensive area of the four threshing bars is 43.9-71.9 N, all of which are in the safe area under the load of 2 times, 4 times, and 6 times, indicating that the internal damage degree of rice grains is $0 \%$ at this time; (3) There are a few cases where the force of the threshing bar will cause 5\%-10\% internal damage to the rice grains, but there is no case where the internal damage exceeds $10 \%$; (4) The critical force of the same internal damage degree decrease with the increase of the number of loading times.

\section{Conclusions}

(1) According to the static compression test of rice grains, the destructive force of the positive pressure mode is greater than the lateral pressure, and the lateral pressure is greater than the vertical pressure, which are $132 \mathrm{~N}, 111 \mathrm{~N}, 86 \mathrm{~N}$, respectively; when the destructive force is reached, the magnitude of the deformation caused by the three pressure conditions is ranked that vertical pressure is greater than lateral pressure while lateral pressure is greater than positive pressure, which are $0.87 \mathrm{~mm}, 0.56 \mathrm{~mm}$, $0.46 \mathrm{~mm}$, respectively. Combined with the internal damage model, the ranking of the internal damage caused by the same load under three pressure conditions is as follows: vertical pressure is greater than lateral pressure while lateral pressure is greater than positive pressure. Under the condition of vertical pressure, the grains are damaged by crack first, and the damage is the most serious.

(2) Regression evaluation indexes were obtained by fitting the results of the compression test of rice with multiple load values and multiple loading times: the SSE value is 23.65 , the $R^{2}$ is 0.9697 , the Adjusted $R^{2}$ is 0.9474 , and the RMSE is 1.256 , the degree of data fitting is high; The results of the fitted internal damage degree function show that when one of the two parameters (the loading times and the value of external force) remains unchanged, the internal damage degree is consistent with the changing trend of another parameter.

(3) Through testing the rice threshing process, we know that the real-time threshing force stability is very low, but the effective threshing force fluctuates greatly. The minimum variance of the effective threshing force of the four threshing bars is $6.4 \mathrm{~N}$ for the third threshing bar, the maximum threshing force is $121.0 \mathrm{~N}$, and the minimum threshing force is $36.4 \mathrm{~N}$, most of which concentrate at 43.9-71.9 N. The minimum effective threshing force of the threshing roller exceeds $1.57 \mathrm{~N}$, which is the connection force between the rice grain and the stalk. The concentrated threshing force is in the safe load area of the grain under 2, 4, and 6 loads, and no internal crack damage occurs; all threshing forces except the first thresher below the critical load value of 5\% internal damage.

\section{Acknowledgements}

This work was supported by the National Natural Science Foundation of China (Grant No. 51705212), Jiangsu Province "Six Talents Peak" High-level Talent Project (GDZB-085), Natural Science Foundation of Jiangsu Province (BK20170553), Open Fund of Jiangsu Key Laboratory of Agricultural Equipment and Intelligent High Technology (JNZ201912) and Jiangsu Province Postgraduate Research and Innovation Project (KYCX20_3086).

\section{[References]}

[1] Wang Y, Wei Z, Xing S. Stable plastid transformation of rice, a monocot cereal crop. Biochemical and Biophysical Research Communications, 2018; 503(4): 2376-2379.

[2] Tang Z, Li Y, Zhang B, Wang M L, Li Y M. Controlling rice leaf breaking force by temperature and moisture content to reduce breakage. Agronomy, 2020; 10(5): 628. doi: 10.3390/agronomy10050628.

[3] Li L H, Zhang Y. Advantages, challenges and internationalization strategies of hybrid rice in China. China Rice, 2019; 25(4): 1-4. (in Chinese)

[4] Fu J, Chen Z, Han L J, Ren L Q. Review of grain threshing theory and technology. Int J Agric \& Biol Eng, 2018; 11(3): 12-20.

[5] Sun J, Yang Z M, Guo Y M, Cui Q L, Wu X H, Zhang Y Q. Compression mechanical properties and crack formation law of millet grain. Transactions of the CSAE, 2017; 33(18): 306-314. (in Chinese)

[6] Yang Z M, Sun J X, Guo Y M. Effect of moisture content on compression mechanical properties and frictional characteristics of millet grain. Transactions of the CSAE, 2015; 31(23): 253-260. (in Chinese)

[7] Chen Z, Xu Y, Shivkumar S. Microstructure and tensile properties of various varieties of rice husk. Journal of the Science of Food and Agriculture, 2018; 98(3): 1061-1070.

[8] Liang Z W, Li Y M, Xu L Z, Zhao Z. Sensor for monitoring rice grain sieve losses in combine harvesters. Biosystems Engineering, 2016, 147(1): 51-66.

[9] Wang B. Study on mechanism of maize threshing damage and grain harvesting and threshing device. Master dissertation. Hangzhou: Zhejiang University, 2019; 98p. (in Chinese)

[10] Tang Z, Li Y, Li X Y, Xu T B. Structural damage modes for rice stalks undergoing threshing. Biosystems Engineering, 2019; 186(2): 323-336.

[11] Kumar A, Kumar A, Khan K, Kumar D. Performance evaluation of harvesting and threshing methods for wheat crop. International Journal of Pure and Applied Bioscience, 2017; 5(2): 604-611.

[12] Pužauskas E, Steponavičius D, Jotautienė E, Petkevičius S, Kemzūraitė A. Substantiation of concave crossbar shape for corn ear threshing. Mechanics, 2016; 22(6): 553-561.

[13] Xu L, Chen S R, Zhou J, Tang M M, Chen A Y. Experimental study on rice threshing and its influencing factors based on Hege16. Agricultural Mechanization Research, 2019; 41(07): 178-182. (in Chinese)

[14] Wang Z M, Lyu P M, Chen N, Ma G. Study on distribution spectrum of grain connection force and differential-speed threshing device for combine harvester. Journal of Zhejiang University, 2017; 43(1): 120-127. (in Chinese)

[15] Buerano J, Zalameda J, Ruiz R S. Microphone system optimization for free fall impact acoustic method in detection of rice kernel damage. Computers and Electronics in Agriculture, 2012; 85(1): 1-3.

[16] Hasseldine B P J, Gao C, Collins J M, Jung H D, Jang T S, Song J H, et al. Mechanical response of common millet (Panicum miliaceum) seeds under quasi-static compression: experiments and modeling. Journal of the Mechanical Behavior of Biomedical Materials, 2017; 73(2): 102-113.

[17] Teng J Y, Tang J X, Zhang Y N, Li X Y. CT experimental study on the damage characteristics of anchored layered rocks. KSCE Journal of Civil Engineering, 2018; 22(9): 3653-3662.

[18] Yang S Q. Fracturing mechanism of compressed hollow-cylinder sandstone evaluated by X-ray micro-CT scanning. Rock Mechanics and Rock Engineering, 2018; 51(7): 2033-2053.

[19] Du Z, Hu Y G, Buttar N A, Mahmood A. X-ray computed tomography for quality inspection of agricultural products: A review. Food Science \& Nutrition, 2019; 7(10): 3146-3160.

[20] Cantre D, East A, Verboven P, et al. Microstructural characterisation of commercial kiwifruit cultivars using X-ray micro computed tomography. Postharvest Biology and Technology, 2014; 92(4): 79-86.

[21] Ambaw A, Arendse E, Du Plessis A, Opara U L. Analysis of the 3D microstructure of pomegranate peel tissue using X-ray micro-CT. Acta Horticulturae, 2018; 1201(1): 197-204.

[22] Prawiranto K, Defraeye T, Derome D, Bühlmann A, Hartmann S, Verboven $\mathrm{P}$, et al. Impact of drying methods on the changes of fruit microstructure unveiled by X-ray micro-computed tomography. RSC Advances, 2019; 9(19): 10606-10624.

[23] Ou J S, Liu D W, Li X, Ren S G, Xie F P. The research of connecting force of high-yielding rice-case in Hunan Province. Journal of Shanxi Agricultural University (Natural Science Edition), 2016; 36(6): 433-438.

[24] Qu Z. Study on low-damage combined corn threshing separation device. 
Doctoral dissertation. Beijing: China Agricultural University, 2018; 119p. (in Chinese)

[25] Rodrigues G, Weber H, Driemeier L. Elastic and plastic collision comparison using finite element method. International Journal of Mechanical and Mechatronics Engineering, 2019; 13(5): 354-358.

[26] Ma X Y, Lei D T. Experimental study on mechanical properties of soybean seeds. Transactions of the CSAM, 1988; 12(3): 69-75. (in Chinese)

[27] Ojolo J S, Eweina B A. Predicting cashew nut cracking using hertz theory of contact stress. Journal of the Saudi Society of Agricultural Sciences, 2019; 18(2): 157-167.

[28] Wu J, Zhang H, Li F. A study on drying models and internal stresses of the rice kernel during infrared drying. Drying Technology, 2017; 35(6): 680-688.

[29] Chen S R, Xu L, Yin J J, Tang M M. Quantitative characterization of grain internal damage and $3 \mathrm{D}$ reconstruction based on Micro-CT image processing. Transactions of the CSAE, 2017, 33(17): 144-151. (in Chinese)
[30] De-Deus G, Belladonna F G, Silva E J N L, Souza E M, de Azevedo Carvalhal J, Perez R, et al. Micro-CT assessment of dentinal micro-cracks after root canal filling procedures. International Endodontic Journal, 2017; 50(9): 895-901.

[31] Wang G, Guan Z H, Mu S L, Tang Q, Wu C Y. Optimization of operating parameter and structure for seed thresher device for rape combine harvester. Transactions of the CSAE, 2017; 33(24): 52-57. (in Chinese)

[32] Xu L, Li Y M. Analysis on the critical speed of impact damage of rice grains. Transactions of the CSAM, 2009; 40(8): 54-57. (in Chinese)

[33] Jain S, Shukla S, Wadhvani R. Dynamic selection of normalization techniques using data complexity measures. Expert Systems with Applications, 2018; 106(4): 252-262.

[34] Huang D M, Zhou S X, Litak G. Analytical analysis of the vibrational tristable energy harvester with a RL resonant circuit. Nonlinear Dynamics, 2019; 97(7): 663-677.

[35] Tang Z, Wang M L, Zhang H T, Zhou Y P, Yu Y. Variation and modal characteristic of tangential threshing cylinder undergoing threshing dynamics. Mathematical Problems in Engineering, 2020; 2020(12): 1-15. 